\title{
Fullerenol-Capped Porous Silica Nanoparticles for pH-Responsive Drug Delivery
}

\author{
Nikola Ž. Knežević, ${ }^{1}$ Sanja Milenković, ${ }^{2}$ Danica Jović, ${ }^{2}$ Slavica Lazarevic, ${ }^{1}$ \\ Jasminka Mrdjanović, ${ }^{3}$ and Aleksandar Djordjevic ${ }^{2}$ \\ ${ }^{1}$ Faculty of Technology and Metallurgy, University of Belgrade, Karnegijeva 4, 11000 Belgrade, Serbia \\ ${ }^{2}$ Faculty of Science, Department of Chemistry, Biochemistry and Environmental Protection, University of Novi Sad, \\ Trg Dositeja Obradovića 3, 21000 Novi Sad, Serbia \\ ${ }^{3}$ Oncology Institute of Vojvodina, Faculty of Medicine, University of Novi Sad, Put Dr. Goldmana 4, \\ 21204 Sremska Kamenica, Serbia
}

Correspondence should be addressed to Nikola Ž. Knežević; nikola.z.knezevic@gmail.com and Aleksandar Djordjevic; aleksandar.djordjevic@dh.uns.ac.rs

Received 13 April 2015; Accepted 6 July 2015

Academic Editor: Antonio Riveiro

Copyright (C) 2015 Nikola Ž. Knežević et al. This is an open access article distributed under the Creative Commons Attribution License, which permits unrestricted use, distribution, and reproduction in any medium, provided the original work is properly cited.

Novel nanocomposite containing fullerenol nanoparticles (FNP) and porous silica nanoparticles (PSNs) was constructed and characterized. The capability of FNP to serve as a pore-capping agent and for entrapping 9-aminoacridine (9-AA) inside the pores of the PSN material was also demonstrated. Nitrogen sorption measurements evidence the successful capping of the silica pores while thermogravimetric analysis of FNP loaded PSN indicates the existence of pore-loaded fullerenol molecules. Higher amount of the drug release was noted by exposing the material to weakly acidic conditions in comparison to physiological $\mathrm{pH}$, which may find application in targeted treatment of weakly acidic tumor tissues.

\section{Introduction}

Designing nanosystems for targeted drug delivery to cancer cells has been highly attractive research area in recent years. Nanoparticulate drug carriers have been demonstrated to contain an innate ability to accumulate preferentially in cancer tissues due to enhanced permeability and retention (EPR) effect. In addition, selective cancer targeting was achieved by functionalization of nanoparticulate drug carriers with ligands which have specific interaction with tumoroverexpressed receptors [1-4], or by construction of stimuliresponsive nanotherapeutics $[5,6]$. Acidification-induced triggering of the drug release is also a viable route for selective cancer targeting [7], since extracellular $\mathrm{pH}$ value in tumor tissues is weakly acidic [8]. Various drug delivery systems employing acidification as a drug release-triggering stimulus have been reported $[9,10]$. Porous silicate nanomaterials are among the most versatile platforms for construction of such drug carriers due to their high surface area, capabilities for their functionalization with various organoalkoxysilanes, and possibilities to employ different capping agents for entrapment of drugs inside their porous framework [11-16].

Interestingly though, to the best of our knowledge, there are no literature reports on application of fullerene-based molecules as pore blockers in porous silicate-drug carriers, even though their diameter (ca. $1 \mathrm{~nm}$ ) and bulky, spherical morphology seem suitable for such application. Fullerenol, hydroxylated fullerene, was also shown to be capable of reducing side effects of cytotoxic drugs such as doxorubicin [17], which is certainly an additional benefit of constructing fullerenol-containing drug delivery [18]. Furthermore, FNP may attain even more active role in anticancer treatment, upon stimulation with light, since it showed potential for photosensitive generation of reactive oxygen species (ROS) [19]. Recent in vivo experiments have also demonstrated important inhibition of angiogenesis and metastasis processes of cancer tissues by the presence of FNP [20]. 
In this paper, we report on construction and characterization of FNP-PSN nanocomposite for entrapment of anticancer drug 9-aminoacridine (9-AA) inside the pores of silica nanoparticles. The capabilities of the constructed nanocomposite for drug delivery upon exposure to mildly acidic aqueous environment are monitored by UV/VIS absorption measurements of the released drug.

\section{Materials and Methods}

Hexadecyltrimethylammonium bromide (CTAB), $w \geq 98 \%$, tetraethyl orthosilicate (TEOS) $w \geq 99 \%$, fullerene $\mathrm{C}_{60} w \geq$ $95 \%$, and 9-aminoacridine hydrochloride hydrate (9-AA) were commercially available (Sigma-Aldrich).

2.1. Instruments and Methods. Infrared spectra were collected on Thermo Nicolet Nexus 670 FTIR spectrometer; UV/VIS measurements were performed on Scientific Equipment Cintra 1010. Thermogravimetric analysis (TGA) was done on TA Instrument SDT Q600 up to $800^{\circ} \mathrm{C}$ in air with a heating rate $20^{\circ} \mathrm{C} / \mathrm{min}$. Scanning electron micrographs (SEM) were obtained on JEOL JSM 6460 LV microscope. For measurements, the sample was coated with about $2 \mathrm{~nm}$ thick layer of gold. The specific surface areas and pore size distribution of the samples were estimated using nitrogen adsorption-desorption isotherms with Micrometrics ASAP 2020 instrument. Before the sorption measurement, samples were degassed at $105^{\circ} \mathrm{C}$ for $10 \mathrm{~h}$ under reduced pressure. The specific surface area of sample $\left(S_{\mathrm{BET}}\right)$ was calculated according to the Brunauer, Emmett, and Teller (BET) method from the linear part of the nitrogen adsorption isotherm [21]. The total pore volume $\left(V_{\text {tot }}\right)$ was given at $p / p_{0}=0.998$. The volume of the mesopores and pore size distribution were analyzed according to the Barrett, Joyner, and Halenda (BJH) method from the desorption isotherm [22]. The volume of the micropores was calculated according to $\alpha$-plot analysis.

\subsection{Syntheses of Materials}

2.2.1. Synthesis of Porous Silica Nanoparticles (PSNs). Solution of CTAB $(1.00 \mathrm{~g}, 2.74 \mathrm{mmol})$ and $\mathrm{NaOH}(\mathrm{aq})(2.00 \mathrm{~mol} / \mathrm{L}$, $3.50 \mathrm{~mL}$ ) in $480 \mathrm{~mL}$ of demineralized water was prepared, followed by adjusting the solution temperature to $80^{\circ} \mathrm{C}$. TEOS $(5.00 \mathrm{~mL}, 21.9 \mathrm{mmol})$ was introduced dropwise to the solution and the mixture was allowed to stir for $2 \mathrm{~h}$, giving rise to white precipitate (as-synthesized PSN). The solid product was filtered through a sintered glass funnel, washed with demineralized water and $\mathrm{MeOH}$, and dried in air over night. Removal of the CTAB surfactant template was performed by heating at $60^{\circ} \mathrm{C}$ for $6 \mathrm{~h}$ in a solution of $\mathrm{HCl}$ in methanol $(1 \%, \mathrm{v}: \mathrm{v})$. After the surfactant extraction, the material was additionally washed twice with deionized water and methanol and dried in air.

2.2.2. Synthesis of Fullerenol Nanoparticles (FNP). Fullerenol nanoparticles $\left(\mathrm{C}_{60}(\mathrm{OH})_{24}\right)$ were synthesized according to the previously published procedure from fullerene- $\mathrm{C}_{60}$ through catalytic bromination [23], followed by substitution of bromide with hydroxyl groups [24].
2.2.3. Fullerenol-Loaded PSN Material (FNP@PSN). Fullerenol (5 mg) was measured in a $100 \mathrm{~mL}$ flask and $50 \mathrm{~mL}$ of phosphate buffer (PBS) ( $\mathrm{pH} \mathrm{7.4)} \mathrm{was} \mathrm{added.} \mathrm{The}$ solution was sonicated for $10 \mathrm{~min}$ and stirred over night at room temperature. PSN material $(100 \mathrm{mg}$ ) was then added to the solution of FNP and the suspension was stirred for $24 \mathrm{~h}$ at room temperature. The material was then filtrated through a sintered glass funnel, washed twice with phosphate buffer to remove the excess of FNP, once with methanol, and air-dried.

\subsubsection{Preparation of PSN Material Containing 9-AA and FNP} (FNP/9-AA@PSN). Fullerenol (5.0 mg) was measured in a $100 \mathrm{~mL}$ flask and $50 \mathrm{~mL}$ of phosphate buffer ( $\mathrm{pH}$ 7.4) was added. The solution was sonicated for $10 \mathrm{~min}$ and stirred over night at room temperature. A second flask containing $5.0 \mathrm{mg}(20 \mu \mathrm{mol})$ of 9 -aminoacridine hydrochloride hydrate and PSN material $(100 \mathrm{mg})$ in DMSO $(5.0 \mathrm{~mL})$ was separately stirred for $24 \mathrm{~h}$ at room temperature, after which the solution of FNP in PBS was added. The suspension was then left stirring for another $24 \mathrm{~h}$ at room temperature; material was filtrated through a sintered glass funnel, washed twice with phosphate buffer to remove the excess of FNP, once with methanol, and air-dried. The filtrate was saved for determination of the drug loading.

The amount of loaded drug was determined by a standard curve method. Namely, the standard curve was prepared by measuring UV/VIS absorption of different concentrations of 9-AA in phosphate buffer at $400 \mathrm{~nm}$. The filtrate obtained after the drug loading and capping with FNP was collected, methanol was removed by evaporation, 9-AA absorption of the leftover filtrate was measured at $400 \mathrm{~nm}$, and concentration of the leftover drug was determined from the standard curve. The calculated amount of leftover drug was $13.5 \mu \mathrm{mol}$, which gave the amount of loaded drug $(6.5 \mu \mathrm{mol} / 100 \mathrm{mg}$ of PSN) by subtraction from the starting $20 \mu \mathrm{mol}$ of 9 -AA.

2.3. Measurement of the Amount of Released Drug from FNP/9-AA@PSN as a Function of pH Value of the Release Medium. Three vials containing $5 \mathrm{mg}$ of FNP/9-AA@PSN each were prepared and $5 \mathrm{~mL}$ of phosphate buffer/solution with different $\mathrm{pH}$ values was added to the vials. The final $\mathrm{pH}$ values of the three prepared suspensions were measured and the obtained values were 7.4, 6.8, and 5.8. Suspensions were left stirring at RT for $24 \mathrm{~h}$, after which the suspensions were centrifuged for $10 \mathrm{~min}$ at $12000 \mathrm{rpm}$, and UV/VIS absorbance of the supernatants was measured. The amount of the released drug in each sample was calculated from the absorbance value at $400 \mathrm{~nm}$, with the standard curve method.

\section{Results and Discussion}

Porous silica nanomaterial was obtained by CTAB-templated condensation of TEOS, followed by removal of the surfactant with solution of $\mathrm{HCl}$ in methanol. Particle morphology of the obtained material can be observed on SEM image (Figure 1(a)), which shows spherical particles with the diameter in the range $70-160 \mathrm{~nm}$. Infrared spectrum of PSN (Figure 1(b)) shows that the surfactant was successfully 
TABLE 1: Data obtained by nitrogen sorption measurements.

\begin{tabular}{lccccc}
\hline Sample & $S_{\text {BET }}\left(\mathrm{m}^{2} / \mathrm{g}\right)$ & $V_{\text {mesopores }}\left(\mathrm{cm}^{3} / \mathrm{g}\right)$ & $V_{\text {micropores }}\left(\mathrm{cm}^{3} / \mathrm{g}\right)$ & $V_{\text {total }}\left(\mathrm{cm}^{3} / \mathrm{g}\right)$ & 0.68 \\
\hline PSN & 581.0 & 0.54 & 0.24 & 0.60 \\
FNP@PSN & 356.6 & 0.53 & 0.11 & 0. \\
FNP/9-AA@PSN & 269.3 & 0.47 & 0.08 & 0.51 \\
\hline
\end{tabular}

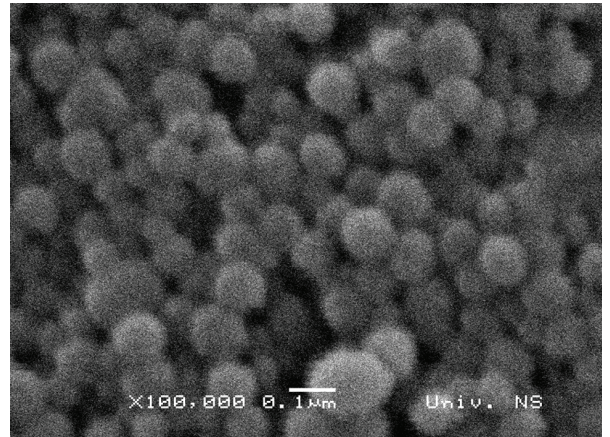

(a)

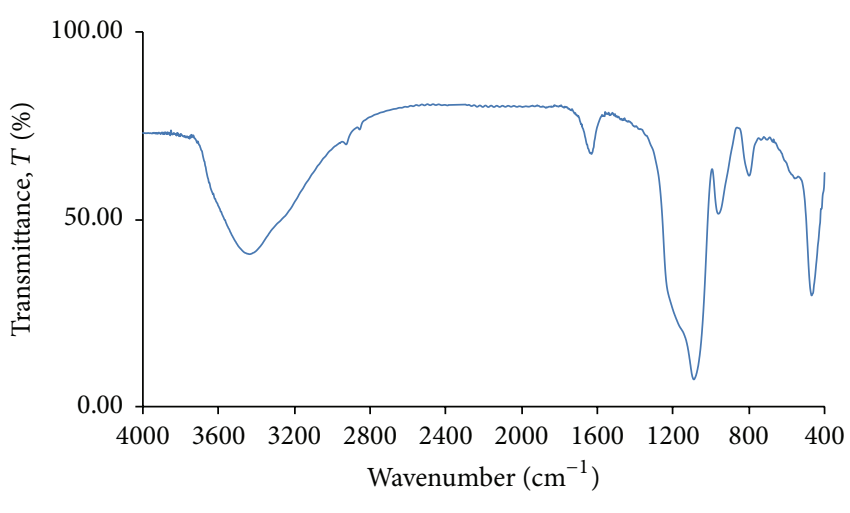

- PSN

(b)

FIGURE 1: (a) SEM image of FNP/9-AA@PSN material and (b) FTIR spectrum of PSN material.

removed after washing, since only a small trace of $\mathrm{C}-\mathrm{H}$ stretching bands was observed at 2925 and $2850 \mathrm{~cm}^{-1}$. The band at $1630 \mathrm{~cm}^{-1}$ can be ascribed to bending vibration of surface-adsorbed water, while the broad band at around $1100 \mathrm{~cm}^{-1}$ is due to various $\mathrm{Si}-\mathrm{O}$ stretching vibrations. Nitrogen sorption measurements of PSN revealed porous nature of the material (Table 1, Figure 2). BET specific surface area of the material decreases from the initial $581 \mathrm{~m}^{2} / \mathrm{g}$ to 356.6 and $269.3 \mathrm{~m}^{2} / \mathrm{g}$ upon loading with FNP and with FNP and 9AA, respectively. This result is indicative of filling the pores of the nanoparticles and, moreover, the pores were more filled (specific surface area is lower) in the presence of 9-AA, which points to successful entrapment of the drug by FNP. As determined, the amount of loaded 9-AA was $66 \mu \mathrm{mol} / \mathrm{g}$ of PSN. In our previous study, we reported that the mesoporous silica nanomaterial, which had much higher specific surface area $\left(1196 \mathrm{~m}^{2} / \mathrm{g}\right)$, was capable of adsorbing maximum of $26.7 \mu \mathrm{mol}$ of 9-AA per gram of material, while specific surface area of the drug-adsorbed material decreased only by $68 \mathrm{~m}^{2} / \mathrm{g}$ [25]. In the current study, even though the surface area of the starting PSN was more than two times lower than the previously reported material, it was capable of loading 2.5 times more of the drug due to the presence of FNP as blocking agents.

The nitrogen sorption isotherms of starting and poreloaded materials (Figure 2(a)) point to the existence of micropores (pore diameter smaller than $2 \mathrm{~nm}$ ) and mesopores (pore diameter in the range of $2-50 \mathrm{~nm}$ ) in the prepared materials [26, 27]. Capillary condensation steps occurring at $p / p^{\circ}=0.9-1.0$ are attributed to the interparticle spacing of PSNs, which are also noted in BJH analyses (Figures 2(b)$2(d))$ as broad peaks in pore size distribution curves in the range of 20-60 nm. BET surface area of the materials and pore volumes of micropores and mesopores as well as the total volume of pores are given in Table 1 . These data point to the successful pore-capping by FNP since a decrease in total pore volume was observed from $0.68 \mathrm{~cm}^{3} / \mathrm{g}$, as calculated for PSN, to $0.60 \mathrm{~cm}^{3} / \mathrm{g}$ and $0.51 \mathrm{~cm}^{3} / \mathrm{g}$ for FNP@PSN and FNP/9AA@PSN, respectively. The mesopore/micropore volume ratios in the synthesized materials are 2.2, 4.8, and 5.9 for PSN, FNP@PSN, and FNP/9-AA@PSN, respectively, which implies that the decrease in the volume of micropores is the most responsible for the decrease in the total pore volume. Furthermore, these data imply that FNP is capable of blocking micropores of the material more efficiently than the mesopores, which is definitely due to the small size of FNP. In the presence of 9-AA, the decrease in pore volumes is even more pronounced, which points to successful entrapment of 9-AA inside the FNP. In the case of PSN and FNP@PSN materials, $\mathrm{BJH}$ calculations did not reveal maximum peaks for pore size distribution (Figures 2(b) and 2(c)), which indicates that the pore volumes in these materials are uniformly distributed across the studied range of pore diameters. However, in the case of FNP/9-AA@PSN material, the mesopores of ca. $3 \mathrm{~nm}$ appeared as the most prevalent (Figure 2(d)), which can be also explained as the result of capping of micropores by FNP. The capped micropores in FNP/9-AA@PSN are eliminated from the pore size distribution calculation, which consequently leaves the mesopores of around $3 \mathrm{~nm}$ as the most prevalent. The fact that this peak in the pore distribution graphs appears only in the case of FNP/9-AA@PSN points to an active role of 9-AA in filling and sealing the micropores, probably through hydrogen bonding and electrostatic interaction of $-\mathrm{NH}_{3}{ }^{+}$moiety from 9-AA with surface silanols from PSN and hydroxyls from FNP. 


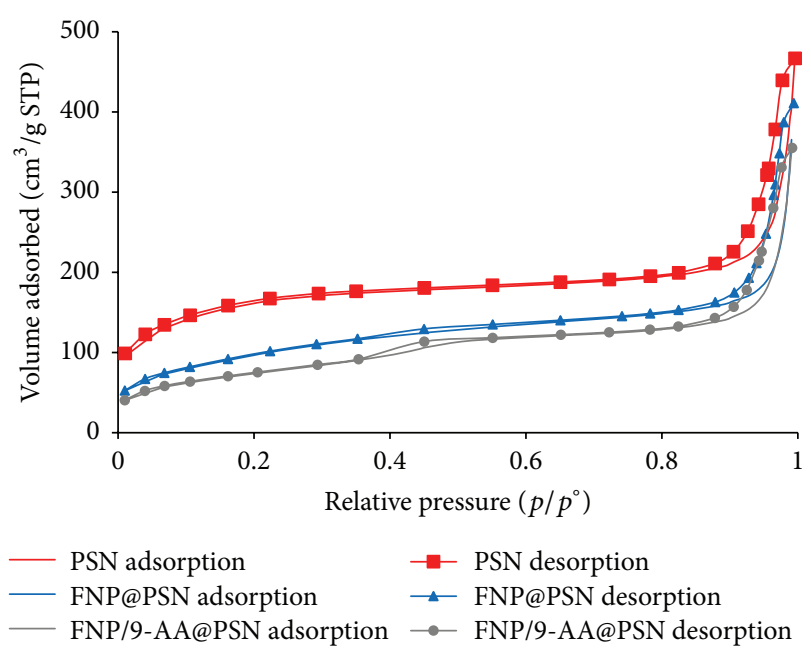

(a)

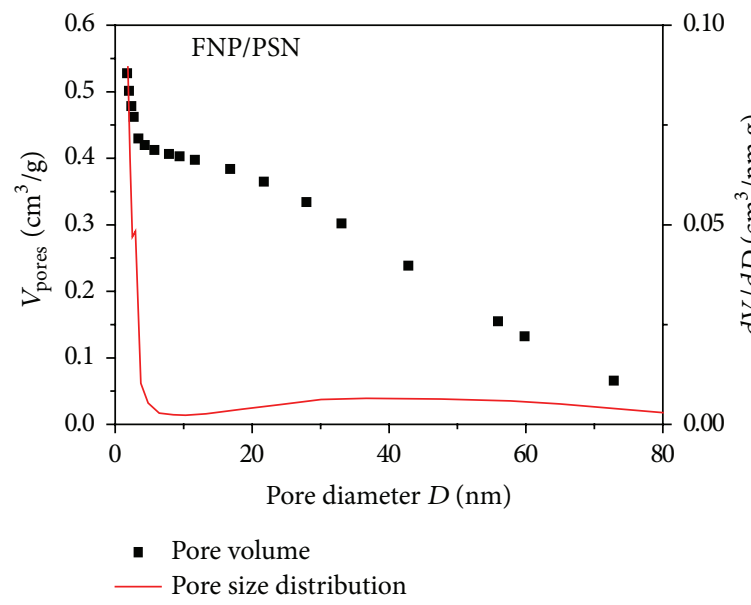

(c)

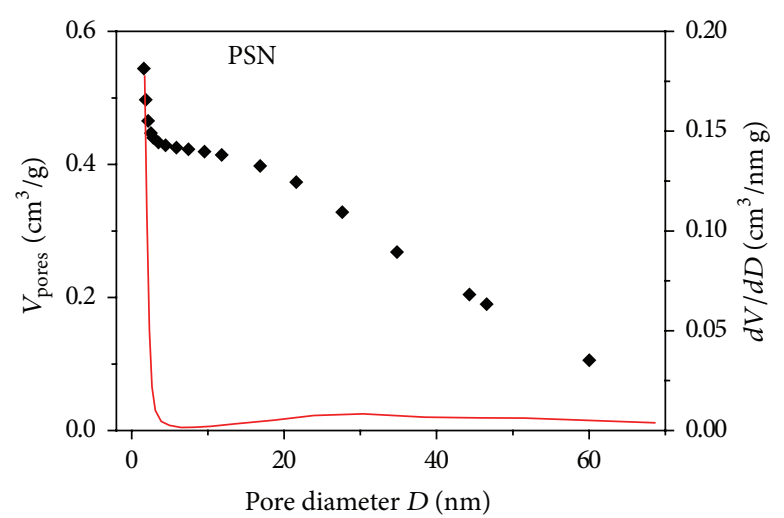

- Pore volume

— Pore size distribution

(b)

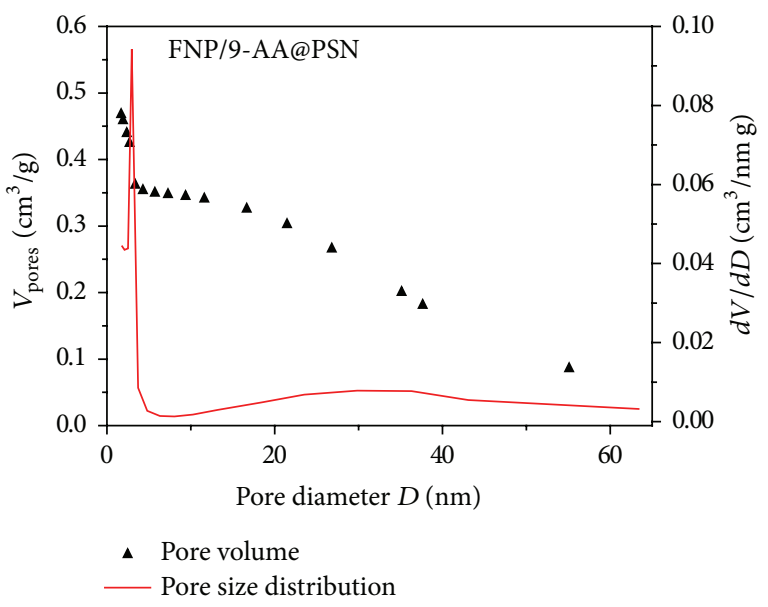

(d)

FIGURE 2: (a) Nitrogen adsorption/desorption isotherms and (b)-(d) BJH pore size volume and size distributions for PSN, FNP@PSN, and FNP/9-AA@PSN.

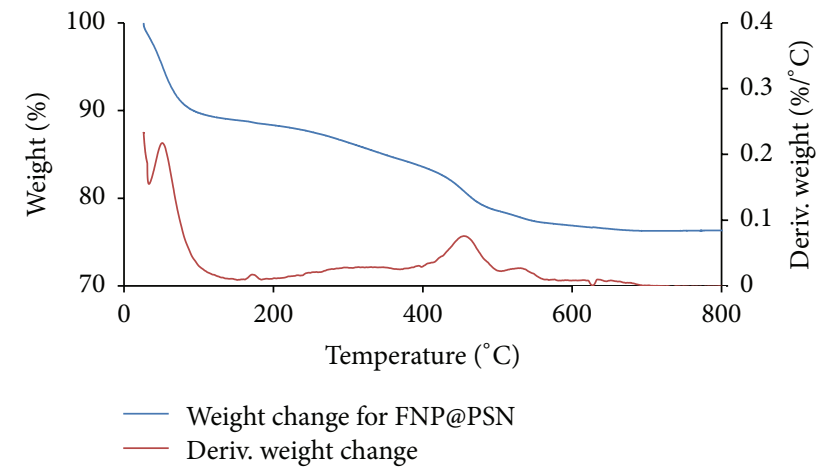

FIGURE 3: Thermogravimetric analysis of FNP@PSN.

Thermogravimetric analysis of FNP@PSN (Figure 3) reveals that the material contains large amount of adsorbed water $(10 \mathrm{wt} \%)$, probably due to involvement of water molecules in the hydrogen bonding between FNP and surface silanols of PSN. The loss of mass was constant by ca. $600^{\circ} \mathrm{C}$ at $77.2 \mathrm{wt} \%$, which allows calculation of the total amount of the loaded FNP (12.8wt\%) without accounting for $10 \%$ of moisture. In the temperature range $200-350^{\circ} \mathrm{C}$, gradual loss of weight is observed, which can be attributed to the loss of $\mathrm{OH}$ groups from the surface of FNP and PSN. Interestingly though, fast degradation of FNP is noted at two different temperatures $\left(455\right.$ and $530^{\circ} \mathrm{C}$ ), which are in fact much lower than the typical starting temperature for rapid degradation of pure FNP (ca. $700^{\circ} \mathrm{C}$ ) [28, 29]. Pure fullerenol owes its high thermal stability to the material stabilization through hydrogen bonding-induced agglomeration of individual molecules. This agglomeration of FNP is prevented inside the pores of PSN due to size constraints, which we believe is the reason for much lower degradation temperatures of pore-loaded FNP.

We further investigated the possibility to release the drug from encapsulation through acidification of the environment. Since the PSN-surface silanols and FNP-surface hydroxyl groups are more protonated with acidification, we expected that their interaction with positively charged 9-AA would weaken, which would consequently lead to separation of the 


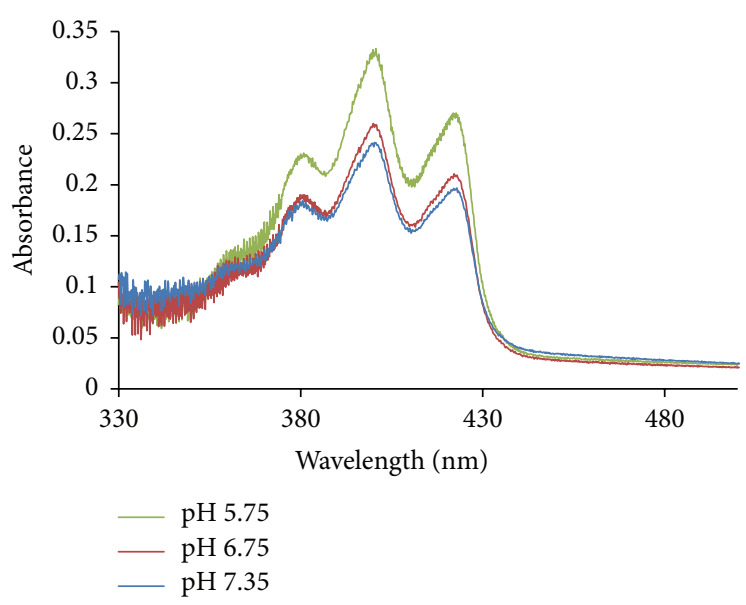

(a)

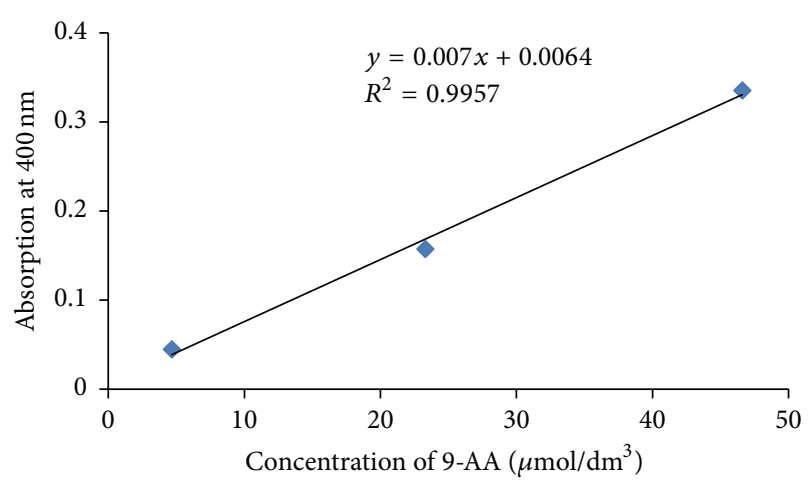

(b)

FIGURE 4: (a) UV/VIS absorbance spectra of 9-AA released from FNP/9-AA@PSN at pH values 7.35, 6.75, and 5.75. (b) Calibration curve for determination of 9-AA concentration.

nanocomposite's constituents and to the release of the drug. To perform the experiment, aqueous phosphate suspensions of different $\mathrm{pH}$ values $(7.35,6.75$, and 5.75$)$ were prepared containing FNP/9-AA@PSN material. After 24 hours of stirring at room temperature, the materials were separated from the bulk solutions by centrifugation and the amounts of UV/VIS absorbing 9-AA molecules contained in the supernatants were measured. Indeed, as can be seen in Figure 4(a), UV/VIS spectra of the supernatants revealed increasing amounts of released 9-AA with lowering $\mathrm{pH}$ values of the environment. The exact amounts of the released drug were calculated based on the calibration curve (Figure 4(b)). At pH 5.75, the material released $45.6 \mu \mathrm{mol}$ of drug, which is $69.1 \%$ of the loaded amount, while at $\mathrm{pH}$ values 6.75 and 7.35 , the material released $36.1 \mu \mathrm{mol}$ and $33.0 \mu \mathrm{mol}$ of the drug which are $54.7 \%$ and $50.0 \%$ of the loaded amount, respectively. These results demonstrate that the constructed material may be applicable for preferential drug delivery to weakly acidic cancer tissues. Further studies are ongoing for optimization of different FNP-capped functionalized porous silica nanoparticles for drug delivery to cancer cells.

\section{Conclusions}

We successfully demonstrated the ability of fullerenols $\left(\mathrm{C}_{60}(\mathrm{OH})_{24}\right)$ to serve as pore-capping agents for construction of porous silica nanoparticle-based drug delivery systems. High amount of the drug was loaded inside the pores of the silica nanoparticles and entrapped due to the presence of surface-adsorbed fullerenols. Release of the drug from the nanomaterial increased with acidification of the environment, which can be applicable for preferential release of drugs under acidic conditions of tumor tissues.

\section{Conflict of Interests}

The authors declare that there is no conflict of interests regarding the publication of this paper.

\section{Acknowledgment}

The authors acknowledge the financial support of the Ministry of Science and Technological Development of the Republic of Serbia (Grant nos. III45005 and III45019).

\section{References}

[1] J. M. Rosenholm, A. Meinander, E. Peuhu et al., "Targeting of porous hybrid silica nanoparticles to cancer cells," ACS Nano, vol. 3, no. 1, pp. 197-206, 2009.

[2] D. P. Ferris, J. Lu, C. Gothard et al., "Synthesis of biomoleculemodified mesoporous silica nanoparticles for targeted hydrophobic drug delivery to cancer cells," Small, vol. 7, no. 13, pp. 1816-1826, 2011.

[3] M. Gary-Bobo, Y. Mir, C. Rouxel et al., "Mannose-functionalized mesoporous silica nanoparticles for efficient two-photon photodynamic therapy of solid tumors," Angewandte ChemieInternational Edition, vol. 50, no. 48, pp. 11425-11429, 2011.

[4] N. Ž. Knežević and J.-O. Durand, "Targeted treatment of cancer with nanotherapeutics based on mesoporous silica nanoparticles," ChemPlusChem, vol. 80, no. 1, pp. 26-36, 2015.

[5] Y. Wang, M. S. Shim, N. S. Levinson, H.-W. Sung, and Y. Xia, "Stimuli-responsive materials for controlled release of theranostic agents," Advanced Functional Materials, vol. 24, no. 27, pp. 4206-4220, 2014.

[6] N. Ž. Knežević, B. G. Trewyn, and V. S.-Y. Lin, "Functionalized mesoporous silica nanoparticle-based visible light responsive controlled release delivery system," Chemical Communications, vol. 47, no. 10, pp. 2817-2819, 2011.

[7] N. Ž. Knežević, B. G. Trewyn, and V. S.-Y. Lin, "Light- and pHresponsive release of doxorubicin from a mesoporous silicabased nanocarrier," Chemistry: A European Journal, vol. 17, no. 12, pp. 3338-3342, 2011.

[8] Y. Kato, S. Ozawa, C. Miyamoto et al., "Acidic extracellular microenvironment and cancer," Cancer Cell International, vol. 13, no. 1, article 89, 2013.

[9] M. Xue, D. Cao, J. F. Stoddart, and J. I. Zink, "Size-selective pHoperated megagates on mesoporous silica materials," Nanoscale, vol. 4, no. 23, pp. 7569-7574, 2012. 
[10] I.-P. Huang, S.-P. Sun, S.-H. Cheng et al., "Enhanced chemotherapy of cancer using $\mathrm{pH}$-sensitive mesoporous silica nanoparticles to antagonize P-glycoprotein-mediated drug resistance," Molecular Cancer Therapeutics, vol. 10, no. 5, pp. 761-769, 2011.

[11] M. Colilla, B. González, and M. Vallet-Regí, "Mesoporous silica nanoparticles for the design of smart delivery nanodevices," Biomaterials Science, vol. 1, no. 2, pp. 114-134, 2013.

[12] Z. Li, J. C. Barnes, A. Bosoy, J. F. Stoddart, and J. I. Zink, "Mesoporous silica nanoparticles in biomedical applications," Chemical Society Reviews, vol. 41, no. 7, pp. 2590-2605, 2012.

[13] Q. He and J. Shi, "MSN anti-cancer nanomedicines: chemotherapy enhancement, overcoming of drug resistance, and metastasis inhibition," Advanced Materials, vol. 26, no. 3, pp. 391-411, 2014.

[14] C. Argyo, V. Weiss, C. Bräuchle, and T. Bein, "Multifunctional mesoporous silica nanoparticles as a universal platform for drug delivery," Chemistry of Materials, vol. 26, no. 1, pp. 435-451, 2014.

[15] S.-H. Wu, C.-Y. Mou, and H.-P. Lin, "Synthesis of mesoporous silica nanoparticles," Chemical Society Reviews, vol. 42, no. 9, pp. 3862-3875, 2013.

[16] N. Z. Knežević, E. Ruiz-Hernández, W. E. Hennink, and M. Vallet-Regí, "Magnetic mesoporous silica-based core/shell nanoparticles for biomedical applications," RSC Advances, vol. 3, no. 25, pp. 9584-9593, 2013.

[17] G. Bogdanović, V. Kojić, A. Dordević, J. Čanadanović-Brunet, M. Vojinović-Miloradov, and V. V. Baltić, "Modulating activity of fullerol $\mathrm{C}_{60}(\mathrm{OH})_{22}$ on doxorubicin-induced cytotoxicity," Toxicology in Vitro, vol. 18, no. 5, pp. 629-637, 2004.

[18] P. Chaudhuri, A. Paraskar, S. Soni, R. A. Mashelkar, and S. Sengupta, "Fullerenol-cytotoxic conjugates for cancer chemotherapy," ACS Nano, vol. 3, no. 9, pp. 2505-2514, 2009.

[19] K. D. Pickering and M. R. Wiesner, "Fullerol-sensitized production of reactive oxygen species in aqueous solution," Environmental Science \& Technology, vol. 39, no. 5, pp. 1359-1365, 2005.

[20] F. Jiao, Y. Liu, Y. Qu et al., "Studies on anti-tumor and antimetastatic activities of fullerenol in a mouse breast cancer model," Carbon, vol. 48, no. 8, pp. 2231-2243, 2010.

[21] F. Rouquerol, J. Rouquerol, and K. Sing, Adsorption by Powders and Porous Solids, Academic Press, London, UK, 1999.

[22] E. P. Barrett, L. G. Joyner, and P. P. Halenda, “The determination of pore volume and area distributions in porous substances. I. Computations from nitrogen isotherms," Journal of the American Chemical Society, vol. 73, no. 1, pp. 373-380, 1951.

[23] A. Djordjević, M. Vojinović-Miloradov, N. Petranović, A. Devečerski, D. Lazar, and B. Ribar, "Catalytic preparation and characterization of $\mathrm{C}_{60} \mathrm{Br}_{24}$," Fullerene Science and Technology, vol. 6, no. 4, pp. 689-694, 1998.

[24] S. M. Mirkov, A. N. Djordjevic, N. L. Andric et al., "Nitric oxidescavenging activity of polyhydroxylated fullerenol, $\mathrm{C}_{60}(\mathrm{OH})_{24}$," Nitric Oxide, vol. 11, no. 2, pp. 201-207, 2004.

[25] N. Ž. Knežević, I. I. Slowing, and V. S.-Y. Lin, “Tuning the release of anticancer drugs from magnetic iron oxide/mesoporous silica core/shell nanoparticles," ChemPlusChem, vol. 77, no. 1, pp. 48-55, 2012.

[26] M. Thommes, "Physical adsorption characterization of nanoporous materials," Chemie-Ingenieur-Technik, vol. 82, no. 7, pp. 1059-1073, 2010.

[27] K. S. W. Sing, "Reporting physisorption data for gas/solid systems with special reference to the determination of surface area and porosity (recommendations 1984)," Pure and Applied Chemistry, vol. 57, no. 4, pp. 603-619, 1985.
[28] T. H. Goswami, B. Nandan, S. Alam, and G. N. Mathur, "A selective reaction of polyhydroxy fullerene with cycloaliphatic epoxy resin in designing ether connected epoxy star utilizing fulerene as a molecular core," Polymer, vol. 44, no. 11, pp. 32093214, 2003.

[29] T. H. Goswami, R. Singh, S. Alam, and G. N. Mathur, "Thermal analysis: a unique method to estimate the number of substituents in fullerene derivatives," Thermochimica Acta, vol. 419, no. 1-2, pp. 97-104, 2004. 

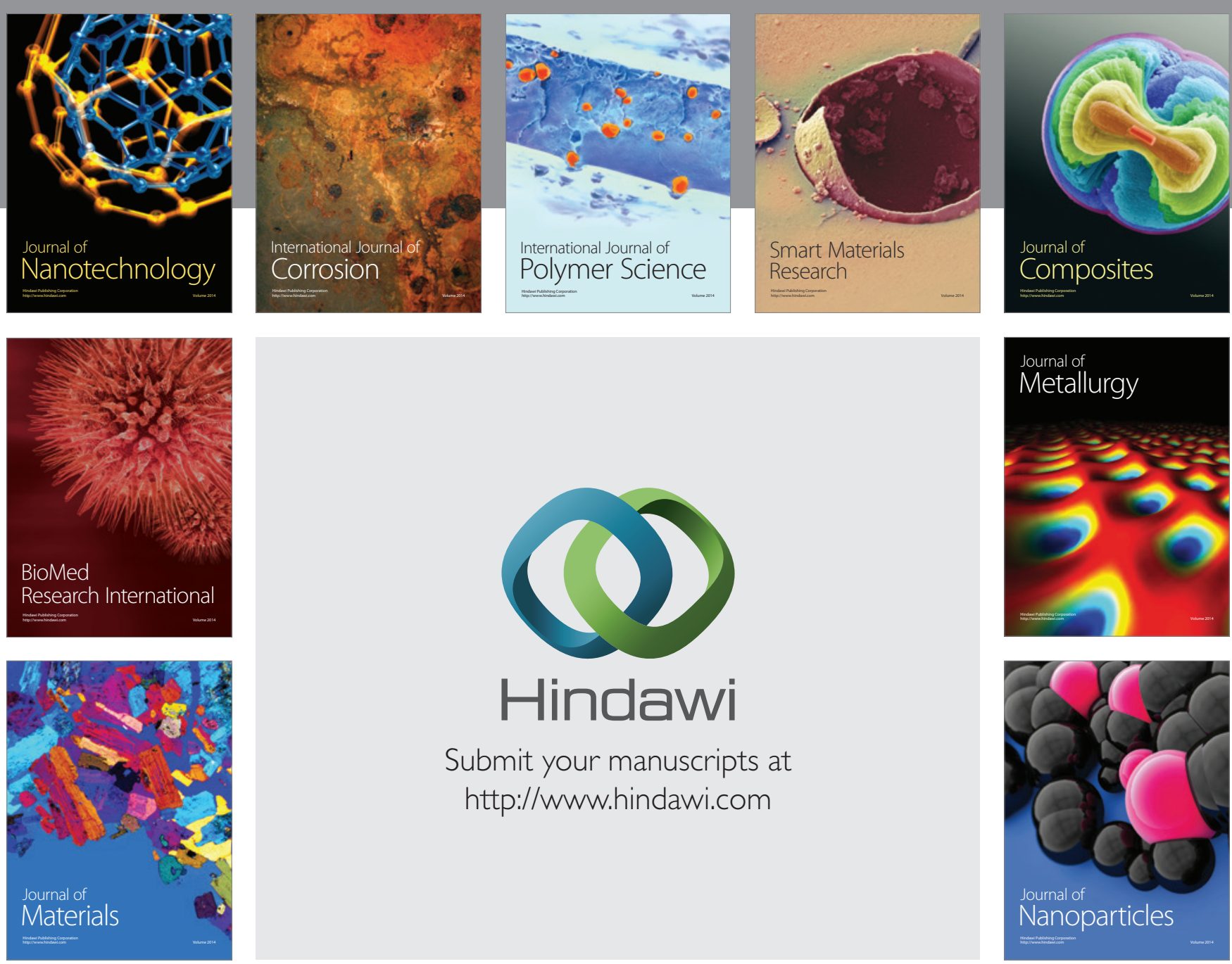

Submit your manuscripts at http://www.hindawi.com
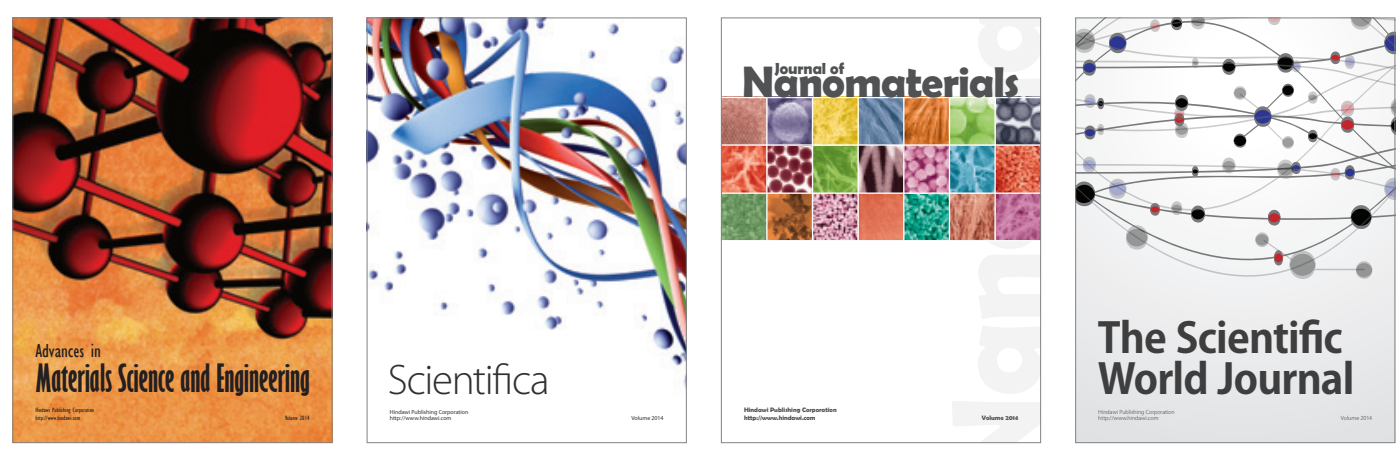

\section{The Scientific World Journal}
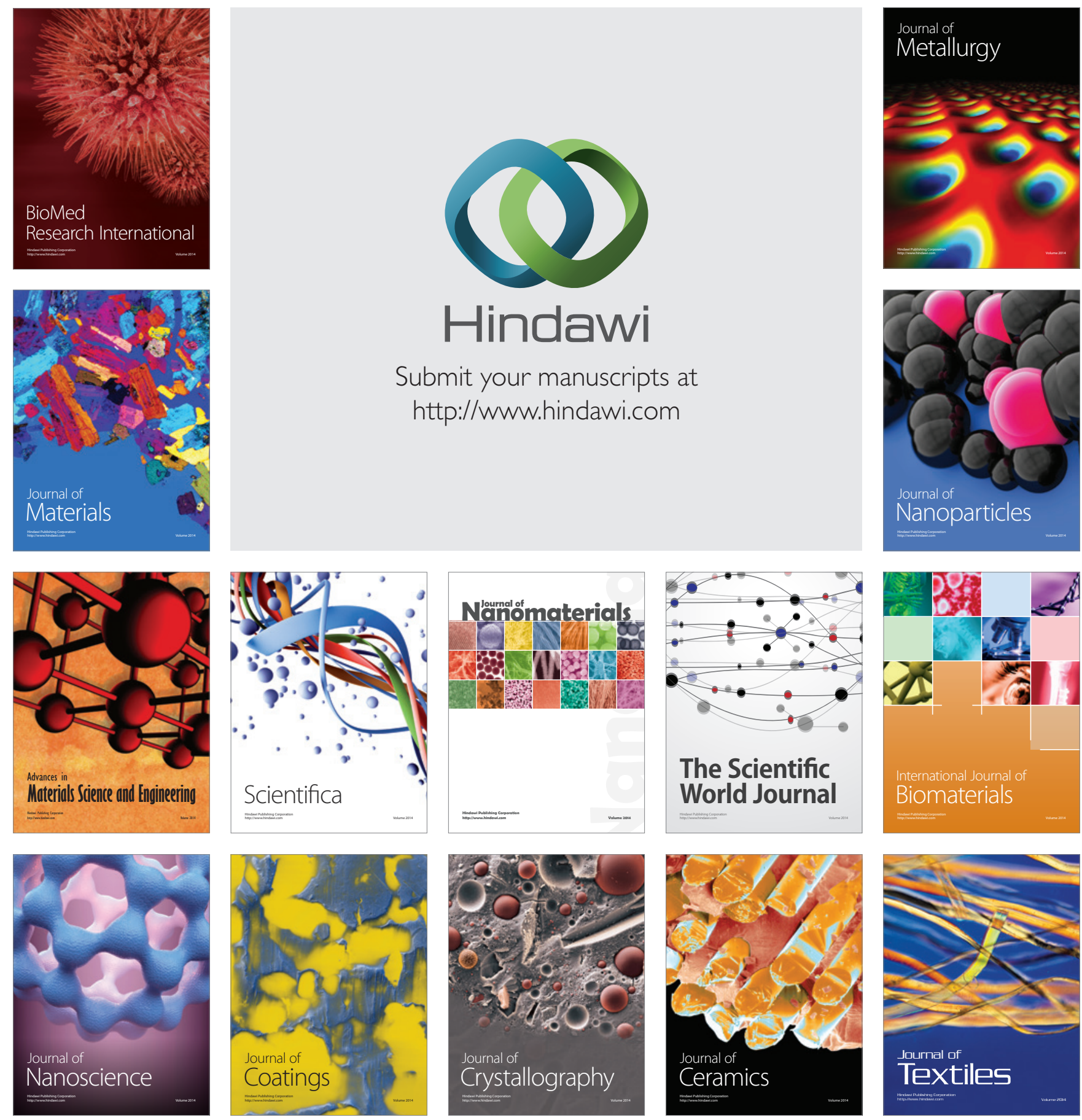